\title{
Key Components for a Successful Wood Bioenergy Project
}

11 ood bioenergy projects are a relatively new industry in Canada and each requires serious thought of what are the key components of the project and the management skills to implement it. As with any business project, the key components can be divided into the following major categories: feedstock supply and storage, technology, finance and legal requirements, and human resources. Each of these must be addressed and each will provide challenges. Clear communication among the people involved in the project is absolutely essential. This article will try to address the practical key challenges within each category, and how to solve problems that may arise. The chart below outlines the key components.

\section{Feedstock supply}

In order to be successful you must first assess the availability of potential feedstocks and the cost to procure along with storage and delivery requirements to meet the operational needs of the bioenergy operation. Suitable feedstocks may be procured through private woodlots, Crown forests, local landfills or by diverting wood waste from other operations. The key sustainability question is determining who controls or owns the feedstock supply. If you are not in a position to directly control the supply, a secure long-term contract is needed that clearly specifies the cost and quantity required, wood quality, delivery methods and schedules. Securing a long-term local supply of quality wood can be very challenging. Even if you directly control the wood supply there may still be challenges related to harvesting, de-limbing, chipping and transportation. Many small communities or local small businesses do not own suitable harvesting machinery or find it too expensive to invest in due to current demands for bioenergy feedstock.

\section{Storage}

Before putting the feedstock into storage it must be screened to remove unwanted materials (rocks, metal) and then protected from further contamination as these items can cause significant damage to the boiler components of the system. Feedstock quality must be pre- served during storage by protecting the wood from moisture, biodegradation and spontaneous combustion.

Wood with its relatively low energy density compared to fossil fuels requires a larger storage capacity. Smaller facilities will require more frequent deliveries, which can add to transportation and fuel costs as well as increasing the carbon footprint of the energy created. Larger storage facilities reduce transport frequencies but will increase the potential for problems with fire that have to be managed.

The main messages for storage are: "keep it clean and keep it dry" and remember to include the ongoing costs associated with maintaining both the feedstock supply and the actual facility. These are both real costs that if overlooked will have a detrimental impact on a bioenergy project.

\section{Technology}

Modern biomass combustion systems are comparable to fuel furnaces in terms of combustion, efficiency and emission levels. For a successful wood bioenergy project you have to find the system that

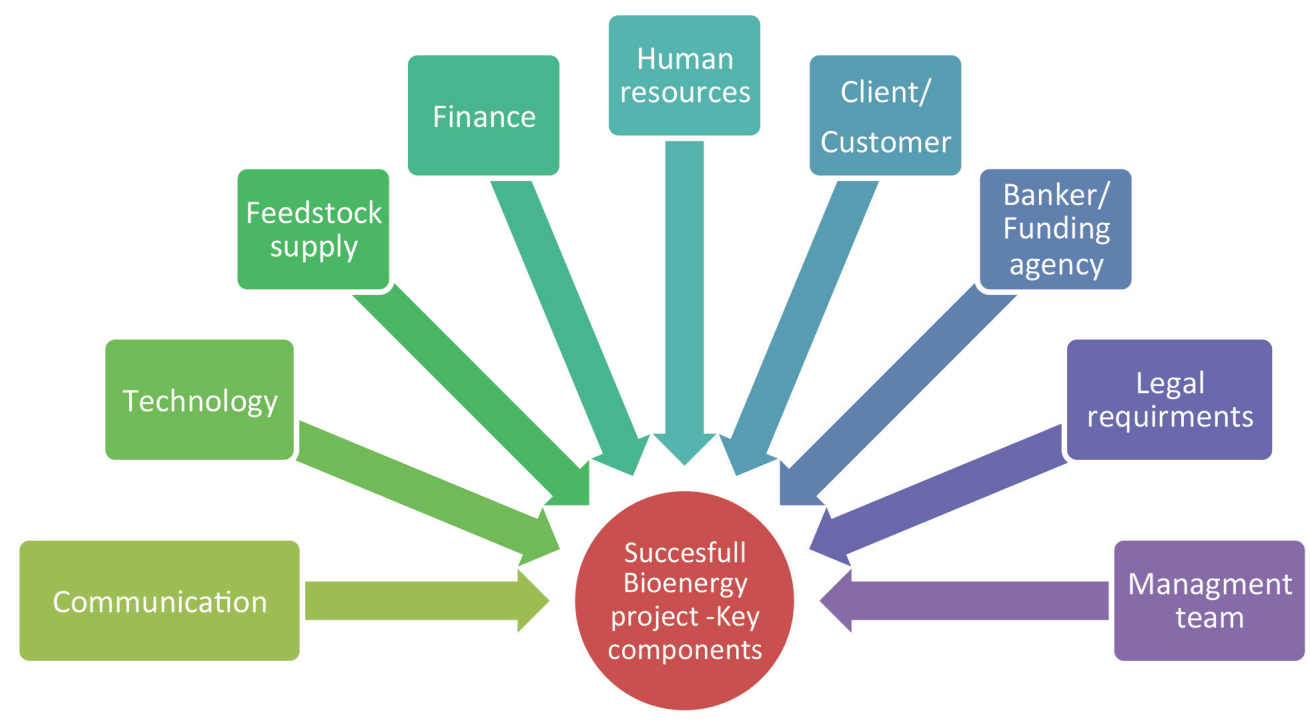


best suits your needs. When choosing a wood boiler system you need to consider:

\section{- Efficiency}

The efficiency of the system is particularly important for economic and environmental reasons. A higher efficiency will allow reductions in fuel consumption and gas emissions to create the same heat demand. Check to ensure the efficiency and capacity of the system will meet current and projected operational requirements.

- Safety/Maintenance

Proper design and installation will ensure a safe work environment. Staff will need to be properly trained on the required safety and maintenance protocols and procedures. Wood boiler dealers vary in their ability to offer service, training and troubleshooting. Make sure you have specified the maintenance needs and the support the supplier will provide to maintain the system and train your staff. These costs are included in the operational plan.

\section{- Automation}

Some modern systems are fully automated, requiring only fuel loading and with minimal maintenance and monitoring. Any bioenergy system will have mechanical parts that may break due to improper operation or using the wrong feedstock. Your staff must have adequate training to operate and maintain the equipment.
- Feedstock storage and space requirements

The system will need sufficient space for itself and for operational feedstock levels. The design of the facility needs to include space for both.

- Emissions

Bioenergy systems can vary in the amount of smoke created through their operation. Confirm the regulations regarding emissions in your jurisdiction before purchasing and installing a system.

\section{Finance and Investment}

As with any business venture there is a need to understand and integrate a multitude of financial components and skills into the project. These include managing cash flow, preparing financial statements, negotiating bank loans, submitting grant applications, establishing contracts with suppliers, purchasing equipment and negotiating lease agreements. These extend beyond the detailed project knowledge of the feedstock costs, production costs and the sales generated in order to meet the requirements of bankers and to attract investors. When managing a bioenergy project, the financial plan must include sound information to support operational component costs: equipment and installation, feedstock, staffing, overheads, and marketing plan.

\section{Human resources}

A crucial component that directly contributes to the success or failure of a bioenergy project is people. Everyone involved in the project must understand their roles and responsibilities and be committed to put their knowledge and skills into action. Without their support there is no amount of technology, perfect feedstock or financing plan that will produce a successful project. Communication among the various parties involved should be constant and clear. Human resources challenges fall into two areas: training and time to deliver the product.

People involved in bioenergy projects must have adequate training to operate the system on a consistent basis and deliver the desired outcomes. It is crucial to include sufficient training time during and after project implementation. It is also essential to select people not only for their knowledge and skills but also for their enthusiasm and commitment to achieving successful project outcomes. This is an additional challenge compared to conventional fossil fuel projects where people have had the opportunity to accumulate decades of experience and knowledge.

Selecting people that have the right mindset, knowledge, and are supported by their colleagues and organization can help drive a successful project and contribute to reaching the full potential of this industry. They must convey a sense of pride in showcasing that bioenergy projects are possible and find it fulfilling to achieve project goals.

For more information, contact Toso Bozic at toso.bozic@gov.ab.ca.

Toso Bozic

Agroforester/Bioenergy Specialist Alberta Agriculture and Rural Development

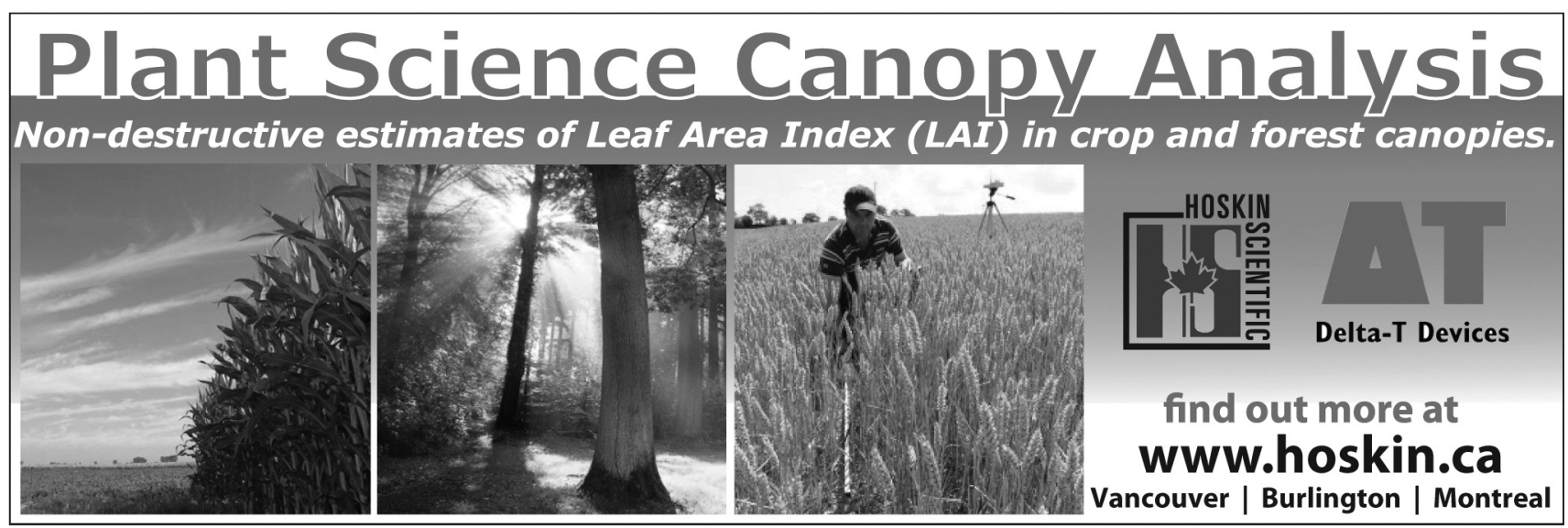




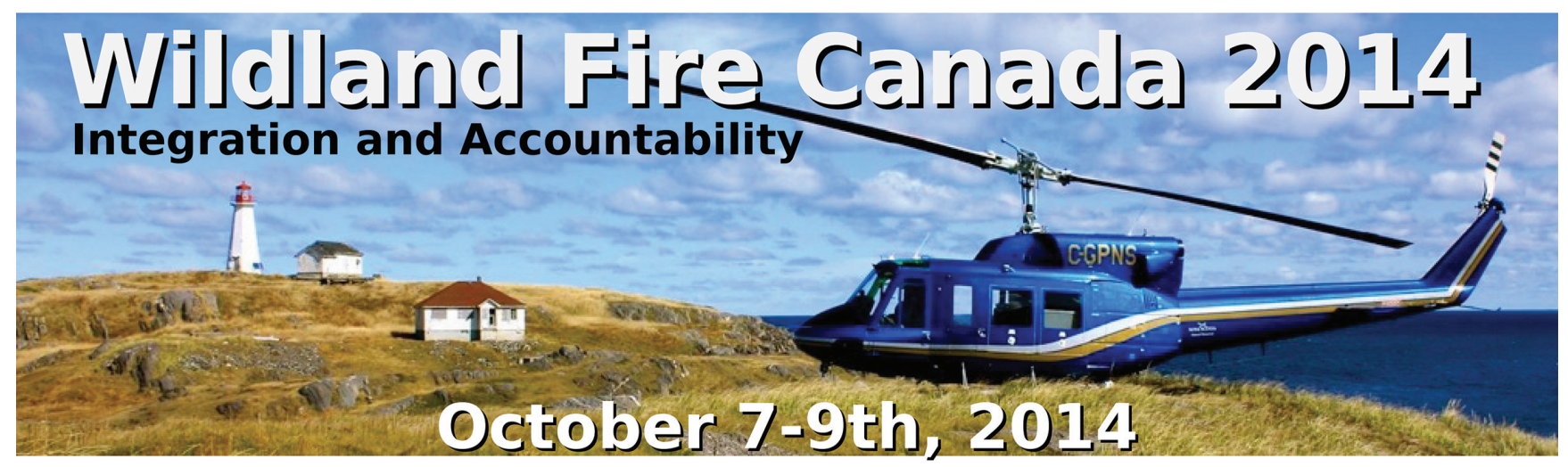

Marriott Harbourfront Hotel, Halifax, Nova Scotia

\section{WildlandFireCanada.ca}

The Wildland Fire Canada Program Committee is currently accepting abstracts on but not limited to the following:

- Historic Fires - Learning from Our Past

- Risk Management and Multiple

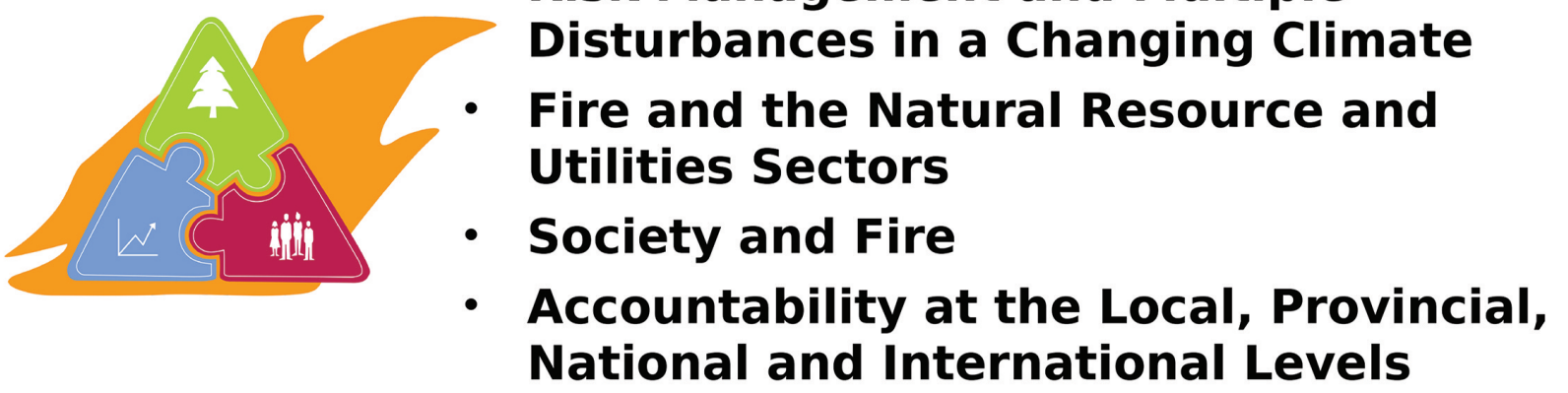

Wildland Fire Canada provides a forum for fire researchers and practitioners to exchange best practices and new ideas. Through the exchange of wildfire knowledge and information, the conference allows attendees to develop a deeper understanding about wildland fires from a variety of perspectives. Building on two successful conferences in 2010 and 2012, the Wildland Fire Canada conference series facilitates partnerships from a multitude of natural resource management and research disciplines.

\section{Abstract deadline: April 15, 2014}

\section{Abstract submission instructions at wildlandfirecanada.ca}

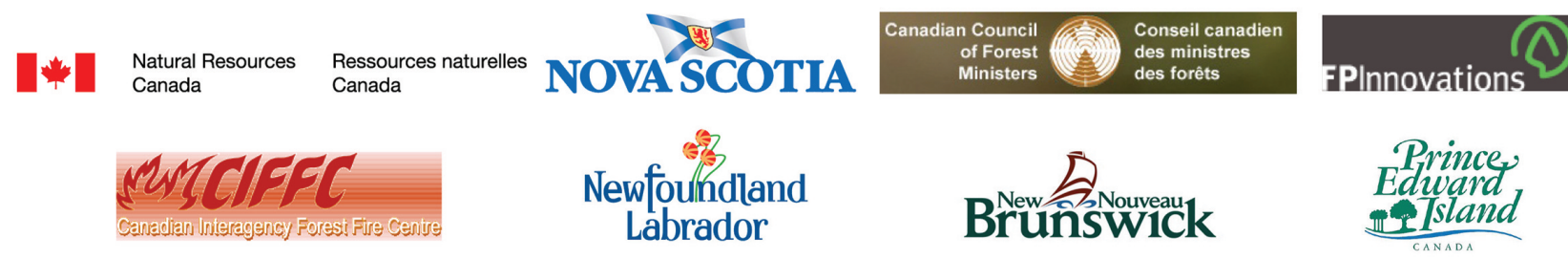



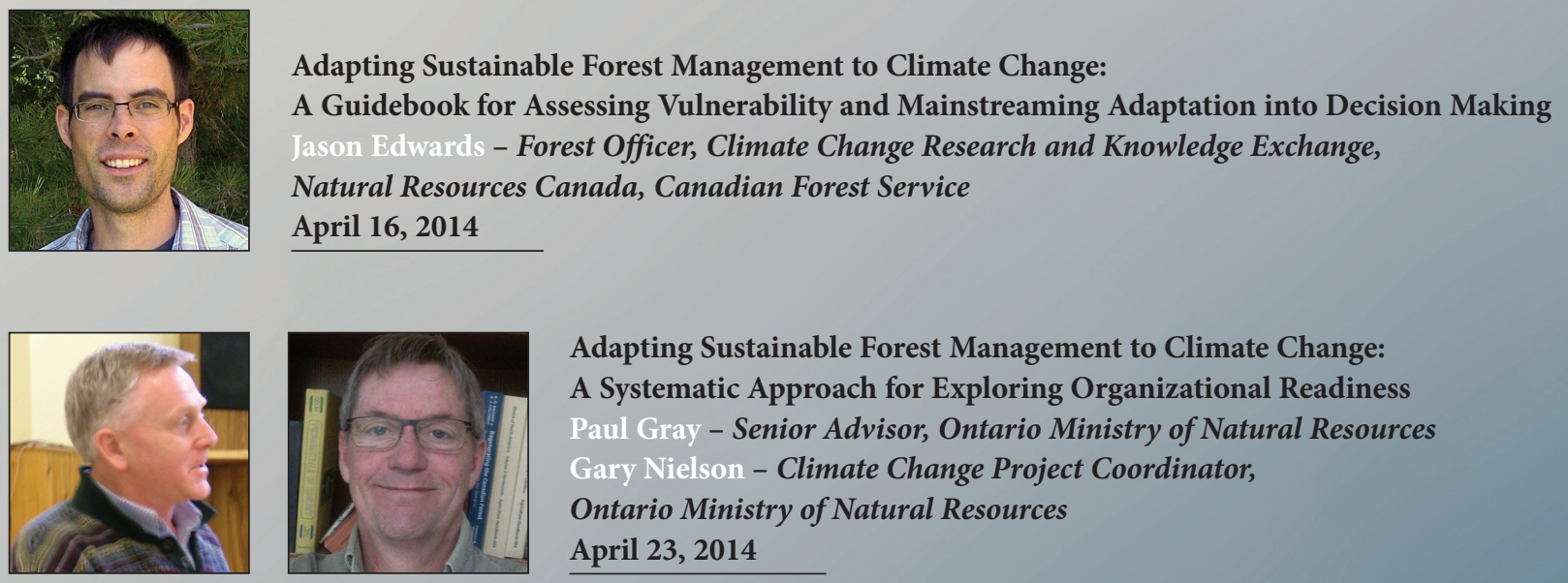

Adapting Sustainable Forest Management to Climate Change: A Systematic Approach for Exploring Organizational Readiness Paul Gray - Senior Advisor, Ontario Ministry of Natural Resources Gary Nielson - Climate Change Project Coordinator, Ontario Ministry of Natural Resources

April 23, 2014
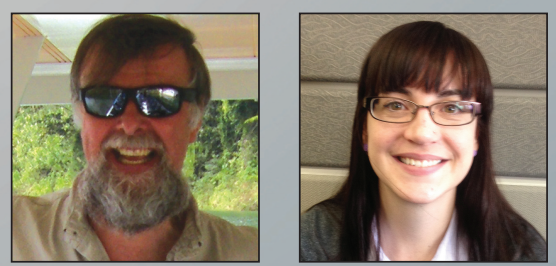

Adapting Sustainable Forest Management to Climate Change:

Scenarios for Vulnerability Assessment

David Price - Research Scientist, Natural Resources Canada, Canadian Forest Service Kendra Isaac - Adaptation Strategy Coordinator, Alberta Environment and Sustainable Resource Development

April 30, 2014
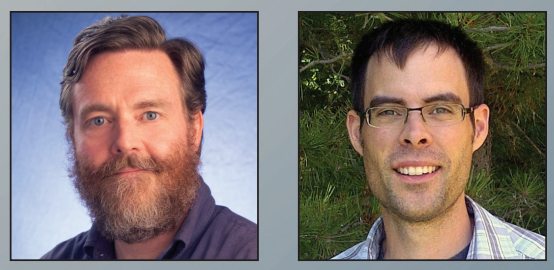

Adapting Sustainable Forest Management to Climate Change: An Analysis of Canadian Case Studies Mark Johnston - Distinguished Scientist, Saskatchewan Research Council Jason Edwards - Forest Officer, Climate Change Research and Knowledge Exchange, Natural Resources Canada, Canadian Forest Service May 7, 2014

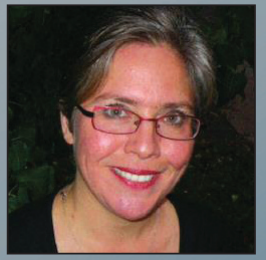

Adapting Sustainable Forest Management to Climate Change: A review of Assisted Migration as a Potential Adaptation Catherine Ste-Marie - Climate Change Science Coordinator, Natural Resources Canada, Canadian Forest Service

May 14, 2014

\section{Canadian Council of Forest Ministers}

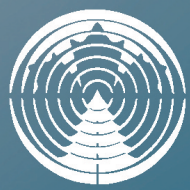

Conseil canadien des ministres des forêts
All electronic lectures are free. Your consideration of CIF/IFC membership would be appreciated. www.cif-ifc.org/site/electure To become a CIF/IFC member: www.cif-ifc.org/site/join 1:30 p.m. ET; 10:30 a.m. PT FOR ADDITIONAL INFORMATION OR TO REGISTER, CONTACT: Canadian Institute of Forestry/ Institut forestier du Canada E-mail: electures@cif-ifc.org Tel: 705-744-1715 ext. $585 \quad$ Fax: 705-744-1716 